\title{
Insuficiencia cardíaca secundaria a distrofia de Steinert
}

\author{
Jiménez M, Besa S, Fajuri A.
}

Resumen: Se presenta el caso de un hombre de 51 años, portador de Distrofia de Steinert, que desarrolla insuficiencia cardíaca congestiva e insuficiencia respi- ratoria. Se describe el tipo de compromiso cardíaco y la evolución del paciente y se discute la prevalencia de insuficiencia cardíaca en estos pacientes. 


\section{Congestive Heart Failure due to Steinert's Muscular Dystrophy. Case report}

A 51 year old male with Steinert's muscular dystrophy is admitted for congestive heart failure, along with his chronic respiratory insufficiency. Presenting findings, treatment and clinical course are described. The preva- lence of heart failure in Steinert's dystrophy is discussed.

Keywords: Muscular dystrophy, Steinert's, Heart Failure 


\section{Introducción:}

La distrofia miotónica tipo 1 (DM1) o enfermedad de Steinert es la distrofia más frecuente en el adulto, con una prevalencia estimada de 1 en $8000 .{ }^{1}$ Se caracteriza por ser un síndrome genético autosómico dominante, con una presentación cada vez más severa y precoz en generaciones sucesivas. Es una enfermedad que produce compromiso multisistémico, incluyendo miotonía, defectos en la conducción cardíaca, catarata ocular, compromiso neurológico y endocrino, entre otros.

Se debe a una repetición anormal del trinucleótido citosina-timina-guanina (CTG) del gen de la protein-kinasa DMPK en el cromosoma 19. A mayor número de repeticiones, mayor severidad de la enfermedad. ${ }^{2}$

En un $80 \%$ de los casos se observa compromiso cardíaco, que se manifiesta principalmente como alteraciones de la conducción. El compromiso de la contractilidad miocárdica es menos frecuente y la falla cardíaca sólo se ve en etapas avanzadas de la enfermedad ${ }^{3-4}$. En el caso descrito a continuación la insuficiencia cardíaca fue, junto a la insuficiencia respiratoria, la forma de presentación.

\section{Caso Clínico}

Hombre de 51 años con antecedentes de Distrofia Miotónica tipo I o de Steinert, insuficiencia cardíaca con capacidad funcional III/IV (NYHA), insuficiencia respiratoria crónica secundaria a hipoventilación alveolar (usuario de BIPAP nocturno) y trastorno de deglución severo con indicación de gastrostomía, la que fue rechazada por el paciente. Refiere historia de múltiples hospitalizaciones por cuadros de insuficiencia respiratoria aguda, con componente infeccioso, requiriendo ventilación mecánica invasiva (VMI) prolongada y traqueostomía en varias oportunidades.

\section{Figura 1.}

Radiografía de tórax A-P portátil. Se aprecia velamiento del tercio inferior de ambos hemitórax e infiltrado intersticial. Silueta cardíaca dentro de límites normales.

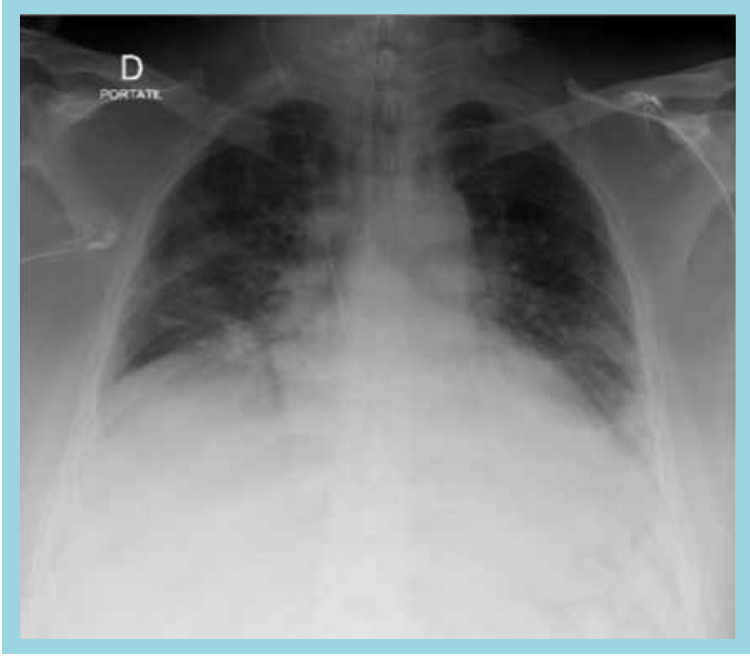

Figura 3.

Ecocardiograma. Visión de eje largo paraesternal.

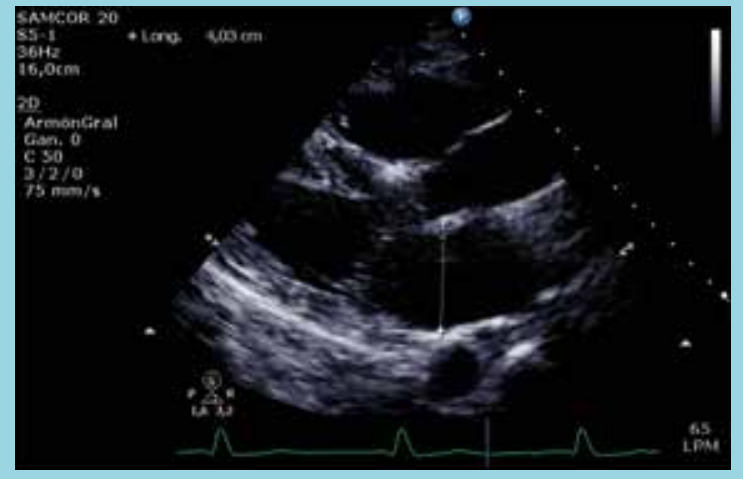

Figura 2. Electrocardiograma. Destaca hemibloqueo izquierdo anterior con acentuadas alteraciones de la repolarización ventricular.

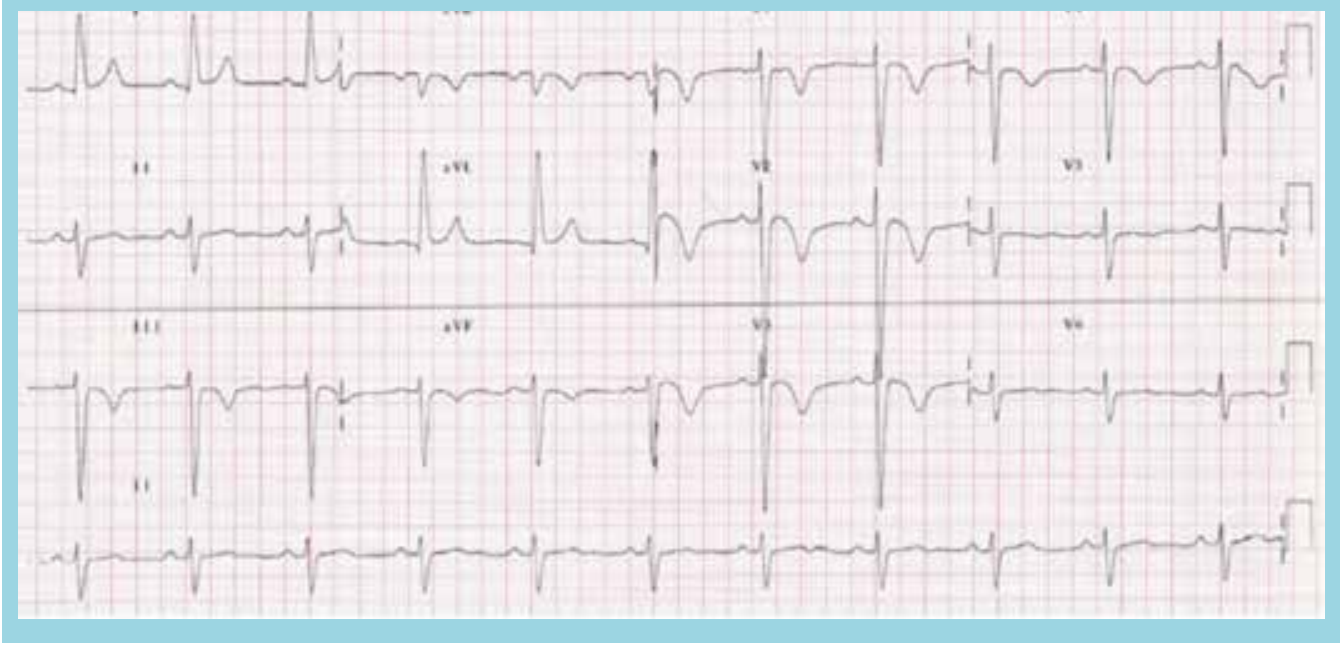


Ocho días previos al ingreso presenta caída con contusión cefálica, evolucionando con compromiso cuali-cuantitativo de conciencia. Posteriormente, se agrega dolor torácico retroesternal, tos y dificultad respiratoria, por lo que acude al servicio de urgencias de nuestro hospital.

Ingresó en malas condiciones generales, soporoso, cianótico, desaturando hasta $78 \%$, mal perfundido y deshidratado. Requirió intubación por mala mecánica ventilatoria, hidratación endovenosa y drogas vasoactivas (inicialmente, levophed, y al ingreso a UCI, dobutamina). Al examen físico destacó una temperatura de $36{ }^{\circ} \mathrm{C}$, frecuencia cardíaca de $75 \mathrm{lpm}$, presión arterial de 88/64 mmHg, saturación de $\mathrm{O} 2$ 92\% con una $\mathrm{FiO} 2$ de $70 \%$ y frecuencia respiratoria de $20 \mathrm{rpm}$, con murmullo pulmonar disminuido bilateralmente, abundantes estertores en ambos campos pulmonares y edema importante en extremidades inferiores, sin soplos ni ruidos agregados al examen cardíaco. La radiografía de tórax portátil al ingreso (Fig. 1) evidenció infiltrado intersticial bilateral y velamiento en el tercio inferior de ambos hemitórax, con silueta cardíaca de tamaño normal. El electrocardiograma (Fig. 2) reveló un hemibloqueo izquierdo anterior y alteraciones de la repolarización cardíaca no evolutivas, con troponinas que resultaron levemente elevadas, pero que no progresaron en la medición seriada. El holter de arritmias mostró un ritmo sinusal, extrasístoles supra ventriculares escasos y extrasistolía ventricular polifocal aislada. El ecocardiograma (Fig. 3) mostró hipertrofia ventricular izquierda concéntrica, con hipoquinesia difusa y movimiento anómalo del septum, compromiso moderado de función sistólica global con fracción de eyección $40 \%$, dilatación leve de aurícula izquierda, ventrículo derecho dilatado con función sistólica global disminuida, hipertensión pulmonar con presión sistólica de arteria pulmonar (PSAP) $50 \mathrm{mmHg}$ y presión venosa central (PVC) elevada con vena cava inferior dilatada de $26 \mathrm{~mm}$, sin colapso inspiratorio. Se manejó con drogas vasoactivas (DVA), terapia depletiva con diuréticos y antibioterapia por sospecha de neumonía aspirativa en el contexto de su trastorno de deglución, con buena respues- ta, logrando suspenderse DVA y ser extubado a los 11 días, para ser dado de alta, posteriormente.

\section{Discusión}

El compromiso cardíaco en los pacientes con DM1 se produce principalmente por fibrosis intersticial, hipertrofia de miocitos e infiltración grasa del tejido. ${ }^{4}$ Estos cambios histopatológicos son los responsables de que una de las principales causas de morbimortalidad sean las alteraciones cardíacas. Lo más frecuente de observar en el curso de esta enfermedad son alteraciones de la conducción de lenta progresión, pudiendo afectarse cualquier parte del sistema de conducción, lo que lleva a PR largo, QRS ancho, bloqueos AV, bloqueos de rama, y también arritmias, tanto supraventriculares como ventriculares, siendo estas últimas potencialmente letales. Si bien puede detectarse alteraciones estructurales y disfunción miocárdica subclínica en un gran número de estos pacientes, es infrecuente (aproximadamente un $2 \%$ de los casos) que se presenten con insuficiencia cardíaca clínicamente evidente. ${ }^{6-8}$

El paciente ingresó por un cuadro de insuficiencia respiratoria aguda sobre crónica con clínica e imágenes compatibles con una insuficiencia cardíaca descompensada. En el ECG se observó un hemibloqueo izquierdo anterior con acentuadas alteraciones de la repolarización ventricular. Estas no fueron evolutivas y no se asociaron a alza enzimática. El ecocardiograma reveló alteraciones compatibles con una miocardiopatía secundaria a la DM1 avanzada (disfunción sistólica y diastólica). Aproximadamente un $20 \%$ de las muertes en la DM1 son debidas a causas cardiovasculares, siendo la segunda causa de muerte después de las causas respiratorias. Al mismo tiempo, se ha reportado un 2-30\% de muertes súbitas, dependiendo de la serie publicada. ${ }^{9}$ Debido a esto, es necesario detectar precozmente en ellos alteraciones cardiológicas, evaluar la función ventricular y estratificar el riesgo de muerte súbita con el objeto de realizar prevención primaria de esta condición. 


\section{Referencias:}

1. MEOLA G. Clinical aspects, molecular pathomechanis$\mathrm{ms}$ and management of myotonic dystrophies. Acta Myol. 2013;32:154-65.

2. TSILFIDIS C, MACKENZIE A, METTLER G, BARCELÓ J, KORNELUK RG. Correlation between CTG trinucleotide repeat lenght and frequency of severe congenital myotonic dystrophy. Nat Genet 1992;1:192-5.

3. NIGRO G, PAPA AA, POLITANO L. The heart and cardiac pacing in Steinert disease. Acta Myol. 2012;31: 110-6.

4. Cabrera Bueno F1, Jiménez-Navarro MF, Ruiz-Ruiz MJ, Gómez-Doblas JJ, Rodríguez-Bailón I, de Teresa E. Insuficiencia cardíaca como manifestación cardiológica inicial de la distrofia miotónica de Steinert. Rev Esp Cardiol. 2001;54:917-9.

5. PHILLIPS MF, HARPER PS. Cardiac disease in myotonic dystrophy. Cardiovasc Res. 1997;33:13-22.
6. PELARGONIO G, DELLO RUSSO A, SANNA T, DE MARTINO G, BELLOCCI F. Myotonic Dystrophy and the heart. Heart. 2002;88:665-70.

7. BHAKTA D1, LOWE MR, GROH WJ. Prevalence of structural cardiac abnormalities in patients with myotonic dystrophy type I. Am Heart J. 2004;147:224-7.

8. DI CORI A1, BONGIORNI MG, ZUCCHELLI G, SOLDATI E, FALORNI M, SEGRETI L, et al. Early left ventricular structural myocardial alterations and their relationship with functional and electricalproperties of the heart in myotonic dystrophy type 1. J Am Soc Echocardiogr. 2009;22:1173-9.

9. MATHIEU J, ALLARD P, POTVIN L, PRÉVOST C, BÉGIN P. A 10 year study of mortality in a cohort of patients with myotonic dystrophy. Neurology 1999;52:1658-62. 